\title{
Inhibition of the peritoneal metastasis of human gastric cancer cells by dextran sulphate in vivo and in vitro
}

\author{
YUANYI XU ${ }^{1 *}$, YUNNING HUANG $^{2 *}$, HONGHONG WANG ${ }^{1}$ and YONG LIU ${ }^{1}$ \\ ${ }^{1}$ Department of Pathology, Ningxia Medical University, Yinchuan, Ningxia 750004; \\ ${ }^{2}$ Department of Gastrointestinal Surgery, Ningxia People's Hospital, Yinchuan, Ningxia 750001, P.R. China
}

Received December 29, 2014; Accepted January 14, 2016

DOI: $10.3892 / 01.2016 .4234$

\begin{abstract}
The present study investigated the inhibitory effects of dextran sulphate (DS) on the peritoneal metastasis of gastric cancer by observing the adhesion and implantation of human gastric cancer cells in the omenta of nude mice. DS or PBS was added to the culture medium of gastric cancer MKN1 cells. The adhesion of the cancer cells to the culture dishes, and the morphological changes of fixed and living cancer cells were observed using fluorescence staining and confocal microscopy. In addition, the expression of integrin $\beta 1$ was measured using immunohistochemistry and reverse transcription-polymerase chain reaction (RT-PCR). Gastric cancer BGC-823 cells were peritoneally injected into nude mice to develop an animal model. DS and PBS were peritoneally injected into the experimental and control groups, respectively, concurrently with the tumour cells. Haematoxylin and eosin staining was performed, and the number of carcinoma nodules with celiac implantation was counted. Integrin expression was determined by immunohistochemistry and RT-PCR. The results showed that MKN1 cells strongly expressed integrin $\beta 1$ in the cell membrane and clustered in vitro. DS inhibited the expression of integrin $\beta 1$ and reduced cluster formation. In addition, the number of pseudopodia formed by the cells decreased, and the cells maintained a rounded shape. The expression of integrin $\beta 1$ in the adherent and free cells in the experimental group was reduced to 74 and $38 \%$ of the levels in the control group, respectively. In the in vivo study, significantly fewer tumour nodules were observed in the experimental group than in the control group $(\mathrm{P}<0.01)$. Integrin $\beta 1$ expression in the experimental group was decreased significantly compared with that in the control group $(\mathrm{P}<0.01)$. The present study indicates that DS inhibits
\end{abstract}

Correspondence to: Professor Yuanyi Xu, Department of Pathology, Ningxia Medical University, 1160 Shengli Street, Yinchuan, Ningxia 750004, P.R. China

E-mail: nxxyy@hotmail.com

*Contributed equally

Key words: dextran sulphate, gastric cancer, integrin $\beta 1$, peritoneal metastasis the adhesion of human gastric cancer cells, accompanied by a decrease in the expression of integrin $\beta 1$. DS may inhibit the metastatic celiac implantation of human gastric cancer cells by downregulating integrin $\beta 1$.

\section{Introduction}

As the second most common cause of cancer-associated mortality in the world, gastric cancer is particularly prevalent in the Far East region (1). Despite recent advances in treatments, gastric cancer is challenging to cure unless it is found at an early stage of disease (2). In general, gastric cancer does not have many typical symptoms, and patients may only display anorexia. Therefore, early diagnosis is difficult unless the patient accepts regular endoscopic examination. Gastric cancer requires comprehensive treatment, including surgery, chemotherapy and radiotherapy; however, once peritoneal metastasis occurs therapy frequently becomes ineffective, although chemotherapy has been used as a clinical treatment $(3,4)$. Peritoneal dissemination is the most frequent pattern of metastasis and recurrence in patients with gastric cancer, and it has been previously reported that the detection rate of free cancer cells in the peritoneal cavity was $44 \%$ in patients with serosal invasion (5). Peritoneal metastasis is an important contributing factor in the mortality of patients with gastric cancer, accounting for $\sim 50 \%$ of such mortalities (6). Pertitoneal metastasis of gastric cancer frequently causes no symptoms, and is commonly diagnosed via ultrasound or computed tomography, though it is also possible to diagnose during surgery (4). Generally, the pathway for gastric cancer peritoneal implantation is considered to be the following: Infiltration of the stomach serosal layer, exfiltration from tumour tissue, transfer into the peritoneal cavity, transformation into biologically active cancer cells and proliferation in the peritoneum to form active, implanted cancerous tissue (7). Cell adhesion is an important step in this the process. Integrin $\beta 1$ is an important $\beta$-subunit of the integrin family, which are a family of adhesion factors. Integrin $\beta 1$ has a mediatory role in the interaction between the extracellular matrix and the cell (8). The abnormal expression of integrin $\beta 1$ is associated with celiac implantation in cancer (9). Studies have shown that dextran sulphate (DS) can prevent the implantation of B-16 melanoma cells in omental milky spots and the peritoneum, and that it can prolong the survival of mice with peritoneal-related 
carcinoma (10). The present study investigated the mechanism of the DS-dependent inhibition of the peritoneal metastasis of gastric cancer cells using in vitro and in vivo assays, and was approved by the Institutional Ethics Committee of Ningxia Medical University.

\section{Materials and methods}

\section{In vitro experimental materials}

Cells and cell culture. The human gastric cancer MKN1 cell line (Institute of Cancer Research Repository of Japan, Tokyo, Japan) was cultured in Roswell Park Memorial Institute (RPMI) 1640 medium with 10\% foetal calf serum (FCS) (both Hangzhou Sijiqing Biological Engineering Company, Hangzhou, China) at $37^{\circ} \mathrm{C}$ under $5 \% \mathrm{CO}_{2}$.

Drug. DS (molecular weight, 500,000 Da; Sigma-Aldrich, St. Louis, MO, USA) was dissolved in phosphate-buffered saline (PBS) at a $2 \%$ concentration and sterilised using a $22-\mathrm{mm}$ filter. The final concentration of DS was $0.3 \%$ in the experimental group. The same volume of PBS was used in the control group.

Antibodies. A rabbit anti-human anti-integrin $\beta 1$ monoclonal antibody (2 mg/ml; catalog no., BA0958-1; Wuhan Boster Biological Engineering Co., Ltd., Wuhan, China). A goat anti-rabbit biotin-conjugated immunoglobulin ( $\mathrm{Ig}) \mathrm{G}(2 \mathrm{mg} / \mathrm{ml}$; catalog no., BA1003; Wuhan Boster Biological Engineering Co., Ltd.) was used to stain for primary antibody. A fluorescein isothiocyanate (FITC)-conjugated rabbit anti-human anti-integrin $\beta 1$ antibody ( $2 \mathrm{mg} / \mathrm{ml}$; catalog no., BA1114; dilution, 1:50; Wuhan Boster Biological Engineering Co., Ltd.) was used to stain for integrin $\beta 1$ in living cells.

\section{In vivo experimental materials}

Cells. The gastric cancer BGC-823 cell line (Repository of Beijing Jin Zijing Biological Pharmaceutical Technology, Ltd., Beijing, China) was cultured in RPMI 1640 medium with $10 \%$ FCS at $37^{\circ} \mathrm{C}$ under $5 \% \mathrm{CO}_{2}$ and $70 \%$ humidity.

Animals. Male BALB/c nude mice at 5-6 weeks of age, weighing 18-22 g, were purchased from Beijing Weitonglihua Experimental Animal Technical Co., Ltd. [animal license SCXX (Beijing), 2006-0009]. The mice were maintained under specific pathogen-free conditions, and provided with aseptic food and water ad libitum.

Drugs and reagents. DS was prepared for the in vivo experiment at a concentration of $0.3 \%$, as aforementioned. FCS and RPMI 1640 medium were used for the cell culture. A polymerase chain reaction (PCR) kit (Advantage for RT-for PCR kit; catalog no., 639505; Takara Biotechnology Co., Ltd., Dalian, China), total RNA kit (RNA-Solv Reagent; catalog no., R6834-01; Omega Bio-Tek, Inc., Norcross, GA, USA) and RT reagent kit [EXONUCLEASE III; catalog no., 9037-44-9; Fermentas, Inc.; Thermo Fisher Scientific (China) Inc., Beijing, China] were used for reverse transcription (RT)-PCR. Rabbit anti-human anti-integrin $\beta 1$ monoclonal antibody was used to detect integrin $\beta 1$ (dilution, 1:100) and goat anti-rabbit biotin-conjugated IgG (dilution, 1:1,000) was used to stain for the primary antibody.

Examination by phase-contrast microscopy. The MKN1 cells $\left(5 \times 10^{4}\right.$ cells/well $)$ were cultured in a $75-\mathrm{ml}$ plate, with DS added to the experimental group. The DS was diluted in PBS at a concentration of $0.3 \%$. The total volume of DS solution was $1 \mathrm{ml}$. The same volume of PBS was used in the control group. The cells were observed under a phase-contrast microscope after $4 \mathrm{~h}$ of culture. In each group, the survival rate was $>90 \%$. The cells in the two groups were then collected for the determination of gene expression.

Immunofluorescence staining. The MKN1 cells were cultured in 35-mm glass-bottom culture dishes coated with poly-L-lactic acid (PLL) in culture medium containing DS or PBS. After $2 \mathrm{~h}$ of culture, the cells were rinsed with PBS, fixed with $4 \%$ formalin/PBS at $37^{\circ} \mathrm{C}$ for $15 \mathrm{~min}$, and then stained with an anti-integrin $\beta 1$ monoclonal antibody (1:100 dilution) at $4^{\circ} \mathrm{C}$ for $12 \mathrm{~h}$. The cells were then stained with the goat anti-rabbit biotin-conjugated $\mathrm{IgG}$ secondary antibody (1:1,000 dilution) for $2 \mathrm{~h}$ in the dark after being rinsed repeatedly with PBS. The stained cells were observed using a confocal microscope (LSM 510; Leica Microsystems GmbH, Wetzlar, Germany).

Integrin $\beta 1$ fluorescent immunostaining of living cells. The cells were cultured in a $0.2 \%$ bovine serum albumin solution containing the FITC-conjugated anti-integrin $\beta 1$ antibody for $90 \mathrm{~min}$. The cells were cultured in a $35-\mathrm{mm}$ glass-bottom culture dish coated with PLL and media containing 10\% FCS after 3 washes in PBS, and then examined in a culture tray with a confocal microscope at $37^{\circ} \mathrm{C}$ under $5 \% \mathrm{CO}_{2}$. At $2 \mathrm{~h}$ after plating, the cells were treated with DS at a final concentration of $0.3 \%$. The cells were then examined 30 and $60 \mathrm{~min}$ after the addition of DS.

Expression levels of integrin $\beta 1 \mathrm{mRNA}$. The expression levels of integrin $\beta 1$ mRNA were determined using a semi-quantitative RT-PCR method. Total RNA was isolated according to the manufacturer's protocol using the RNeasy total RNA kit (RNA-Solv Reagent). Additional purification was achieved by DNaseI digestion (Qiagen China Co., Ltd., Shanghai, China). For RT-PCR analysis, $10 \mu 1$ total RNA was used for first-strand cDNA synthesis using oligo-dT primers $(0.5 \mu \mathrm{l})$ and the SuperScript III First-Strand synthesis system (Invitrogen; Thermo Fisher Scientific, Inc., Waltham, MA, USA). The PCR assay was performed using a Biosafer 9703 PCR machine (Safer China Co., Ltd., Nanjing, China) and AmpliTaq DNA polymerase (Roche Diagnostics, Basel, Switzerland). cDNA quality was checked by PCR of the housekeeping gene $\beta$-actin. Primer pairs for the integrin $\beta 1$ chains were selected according to the sequences published in the GenBank database (National Center for Biotechnology Information, ML, USA). The forward primer for integrin $\beta 1$ was 5'-GCAGTAAGCATC CATTGGACCCGTGGGACACTCTGGATT-3', complementary to bp 2284-2261 of integrin $\beta 1$. The reverse primer was 3'-CGTCATTCGTAGGTATAG-5'. The forward and reverse primers for $\beta$-actin were 5'-GTGGGGCGCCCCAGGCA CCA-3' and 3'-CTTAGCACGCACTGTTATTTCCTC-5', respectively. Primers were purchased from Beijing SBS Genetech Co., Ltd. (Beijing, China), and $1 \mu \mathrm{l}$ of each primer was used. Following the denaturation of cDNA $(2 \mu \mathrm{l})$ at $95^{\circ} \mathrm{C}$ for $5 \mathrm{~min}$, temperature cycling ( 35 cycles) was performed as follows: A denaturation step at $95^{\circ} \mathrm{C}$ for $45 \mathrm{sec}$, a $40-\mathrm{sec}$ annealing step at $56^{\circ} \mathrm{C}$ and a 60 -sec elongation step at $72^{\circ} \mathrm{C}$. 
Table I. Comparison of the number of celiac-implanted metastatic nodules in the groups of nude mice.

\begin{tabular}{|c|c|c|c|c|c|c|c|c|}
\hline Group & $\mathrm{n}$ & day 1 & day 3 & day 7 & day 14 & $\begin{array}{c}\text { Natural } \\
\text { death group }\end{array}$ & F-value & P-value \\
\hline Control & 8 & $0.00 \pm 0.00$ & $2.33 \pm 1.20$ & $15.00 \pm 1.53$ & $27.00 \pm 1.73$ & $31.67 \pm 2.40$ & 55.21 & $<0.001$ \\
\hline Experimental & 10 & $0.00 \pm 0.00$ & $0.67 \pm 0.33$ & $4.33 \pm 1.33$ & $13.83 \pm 1.76$ & $16.33 \pm 1.41$ & & \\
\hline t-value & & - & -1.34 & -5.26 & -5.33 & -5.51 & & \\
\hline P-value & & - & 0.30 & 0.00 & 0.00 & 0.01 & & \\
\hline
\end{tabular}

Table II. Comparison of integrin $\beta 1$ immunoreactivity in the experimental and control groups at different time points.

\begin{tabular}{|c|c|c|c|c|c|c|c|c|}
\hline Group & $\mathrm{n}$ & day 1 & day 3 & day 7 & day 14 & $\begin{array}{c}\text { Natural } \\
\text { death group }\end{array}$ & F-value & P-value \\
\hline Control & 8 & $114.73 \pm 14.38$ & $108.81 \pm 14.95$ & $151.96 \pm 16.74$ & $219.68 \pm 16.24$ & $184.78 \pm 16.63$ & 95.99 & $<0.001$ \\
\hline Experimental & 10 & $52.43 \pm 4.93$ & $52.20 \pm 9.26$ & $7.22 \pm 1.25$ & $175.87 \pm 13.31$ & $128.20 \pm 14.10$ & & \\
\hline t-value & & -4.10 & -3.22 & -8.62 & -2.09 & -2.60 & & \\
\hline P-value & & 0.00 & 0.01 & 0.00 & 0.05 & 0.02 & & \\
\hline
\end{tabular}

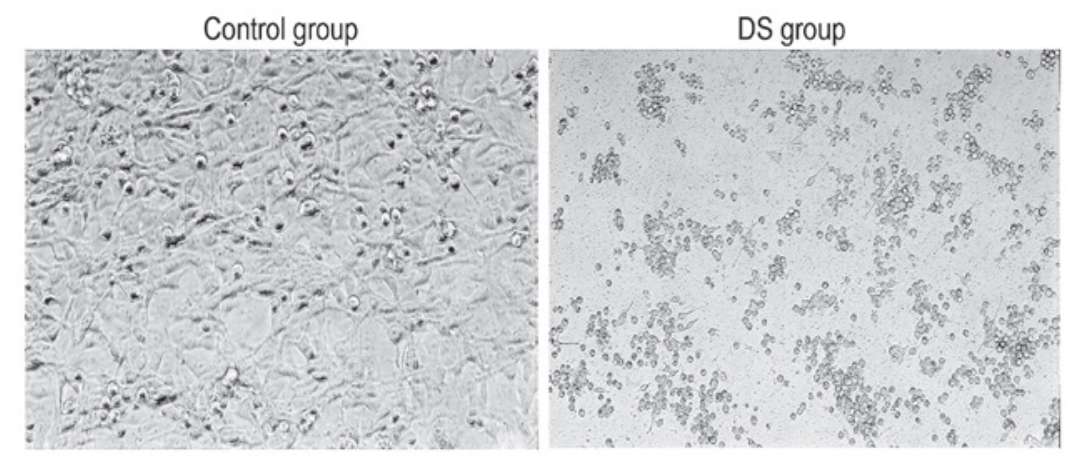

Figure 1. DS causes MKN1 cells to lose connection. In the control group, the MKN1 cells exhibited a spindle or flat morphology, forming a monolayer via mutual contact between the cells after plating for $4 \mathrm{~h}$. In the DS group, a number of the cells were non-adherent. The majority of the adherent cells retained a round shape, and contact between the cells was rarely observed (magnification, $\mathrm{x} 40$ ). DS, dextran sulphate.

Temperature cycling was concluded with a final elongation step for $10 \mathrm{~min}$ at $72^{\circ} \mathrm{C}$. Products $(10 \mu \mathrm{l})$ were analyzed by agarose gel electrophoresis and visualized by ethidium bromide staining under ultraviolet light (Applied Biosystems; Thermo Fisher Scientific, Inc.). The experiment was repeated three times. The relative integrin $\beta 1$ mRNA expression level was calculated in non-adherent and adherent cells from the experimental and control groups. Relative mRNA expression was calculated using the $2^{-\Delta \Delta \mathrm{Cq}}$ method (11) and levels were normalized to the internal control, $\beta$-actin.

\section{In vivo experimental methods}

Establishment of nude mice with celiac implantation of gastric cancer cells. In total, $90 \mathrm{BALB} / \mathrm{c}$ nude mice were randomly divided into the control group $(n=40)$ and the experimental group $(n=50)$, and treated with $0.5 \%$ pentobarbital sodium (50 mg/kg). A gastric cancer BGC-823 cell suspension was intraperitoneally injected at a concentration of $1 \times 10^{7}$ cells $/ \mathrm{ml}$ in a volume of $0.2 \mathrm{ml}$, and $0.3 \% \mathrm{DS}(1 \mathrm{ml})$ was intraperitoneally injected into the experimental group, whereas $0.9 \%$ saline
(1 ml) was intraperitoneally injected into the control group. The entire process strictly adhered to sterile techniques. The control and experimental groups were randomly divided into five groups (control, $n=8$; experimental, $n=10$ ). The mice were sacrificed at 1, 3, 7 and 14 days post-injection, and a natural death group of 5 mice was established in the control and experimental groups. In the natural death group, the mice were sacrificed when the tumor grew to a size that inhibited the ability of the mice to eat. Then the tumor nodules in the peritoneal cavity were taken to be counted and for use in the other experiments. The greater omentum tissue was divided into two sections, one for hematoxylin and eosin (H\&E) and immunohistochemical staining, and another for RT-PCR analysis.

$H \& E$ and immunohistochemical staining. The specimens were processed by formalin fixation, paraffin embedding, slicing, H\&E staining and immunohistochemical staining (streptavidin peroxidase conjugated method). Integrin $\beta 1$ was localized in the cell membrane and cytoplasm. Five representative fields of view were selected. An Image-Pro Plus image 
Table III. Comparison of integrin $\beta 1$ mRNA expression between the experimental and control groups at different time points.

\begin{tabular}{|c|c|c|c|c|c|c|c|c|}
\hline Group & $\mathrm{n}$ & day 1 & day 3 & day 7 & day 14 & $\begin{array}{c}\text { Natural } \\
\text { death group }\end{array}$ & F-value & P-value \\
\hline Control & 8 & $1.17 \pm 0.05$ & $1.30 \pm 0.10$ & $2.44 \pm 0.02$ & $2.67 \pm 0.05$ & $2.06 \pm 0.01$ & 186.13 & $<0.001$ \\
\hline Experimental & 10 & $0.68 \pm 0.03$ & $0.89 \pm 0.03$ & $1.26 \pm 0.04$ & $1.69 \pm 0.02$ & $1.87 \pm 0.06$ & & \\
\hline t-value & - & -7.83 & -3.95 & -25.91 & -17.06 & -3.39 & & \\
\hline P-value & - & 0.00 & 0.04 & 0.00 & 0.00 & 0.02 & & \\
\hline
\end{tabular}

A
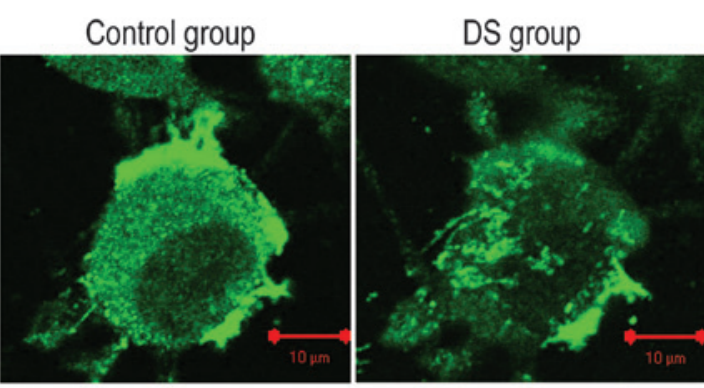

$\mathbf{B}$

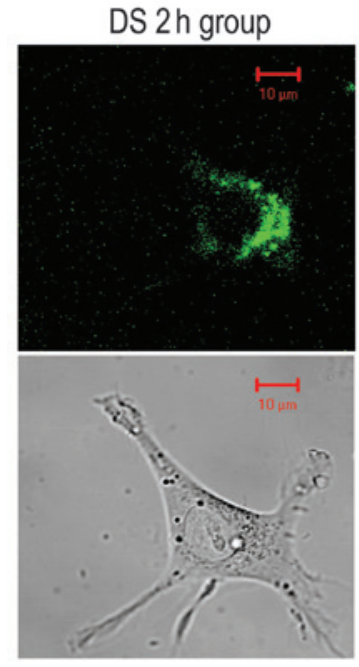

DS 30 min group

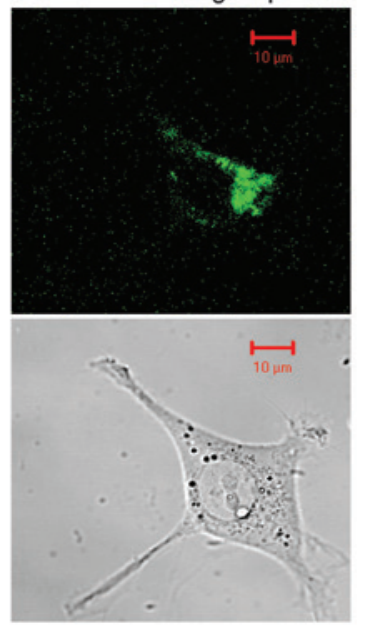

DS 60 min group

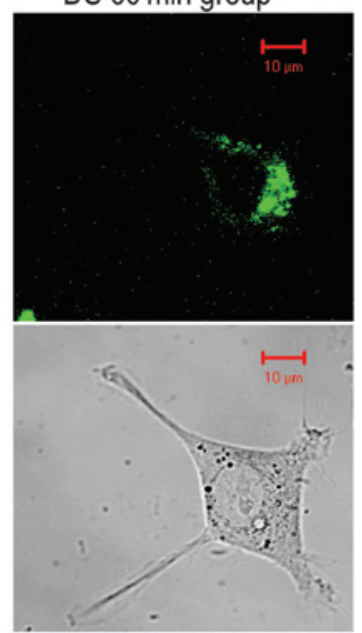

C

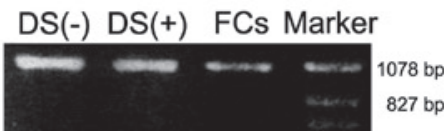

Figure 2. DS inhibits the expression of integrin $\beta 1$ in MKN1 cells. (A) A 488-nm filter was used to detect that the integrin $\beta 1$ was positively expressed in the DS and control groups, and that the level of integrin $\beta 1$ expression was stronger in the control group. (B) The untreated MKN1 cells became flat and formed multiple large pseudopodia. Following treatment with DS for 30 and $60 \mathrm{~min}$, the size of the integrin $\beta 1$ clusters decreased, and the pseudopodia became shorter and then disappeared over time. (C) DS(-) and DS(+) represent the adherent cells of control and DS groups, respectively, while FCs represents the non-adherent cells in the DS group, all expressing integrin $\beta 1$ A DNA ladder is provided as the marker for comparison. The levels of integrin $\beta 1$ mRNA were reduced in the DS group. All fluorescent stains were observed by fluorescence microscopy (magnification, $x 400$ ). DS, dextran sulphate. FCs, non-adherent cells in DS group.

automatic analysis system (Bio-Rad Laboratories, Inc., Hercules, CA, USA) was used to determinate the optical density value and calculate the average optical density (OD) value of the selected field.

$R T$-PCR. The total RNA of the tissue was extracted using a total RNA kit. The primers and the RT-PCR procedure was the same as in the in vitro experiment described previously. The PCR products were separated using $2 \%$ agarose gel electrophoresis with ethidium bromide staining, and images were obtained using a Bio-Rad gel imaging system (Gel Doc $^{\mathrm{TM}} \mathrm{XR}+$, Bio-Rad Laboratories, Inc.). The images were imported into the Quantity One ${ }^{\circledR}$ analysis software (Bio-Rad Laboratories, Inc.) for analysis. The gene expression abundance was represented as the relative OD. The average OD value was calculated as integrin $\beta 1 \mathrm{mRNA}$ abundance / glyceraldehyde-3 phosphate dehydrogenase mRNA abundance. Relative mRNA expression was calculated using the $2^{-\Delta \Delta C q}$ method (11) and levels were normalized to the internal control, $\beta$-actin.

Statistical analysis. SPSS version 21.0 (IBM SPSS, Armonk. NY, USA) was used to perform the statistical analyses. The $\chi^{2}$ test was used for the analysis of categorical variables, which were expressed as numbers and percentages or frequencies. Continuous variables were expressed as the mean \pm standard deviation and were analyzed using the Student's or paired t-test. $\mathrm{P}<0.05$ was considered to indicate a statistically significant difference. 


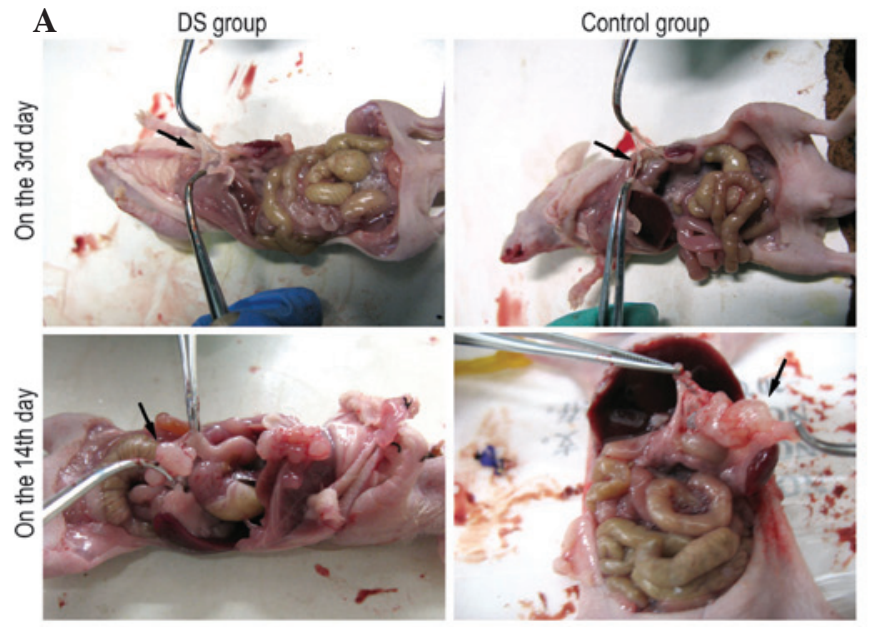

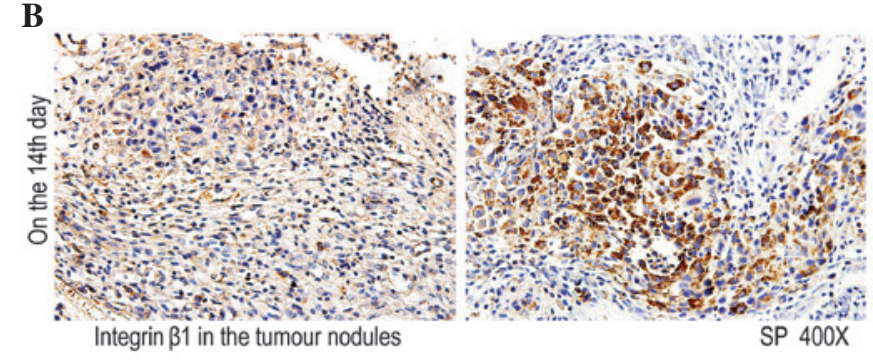

C

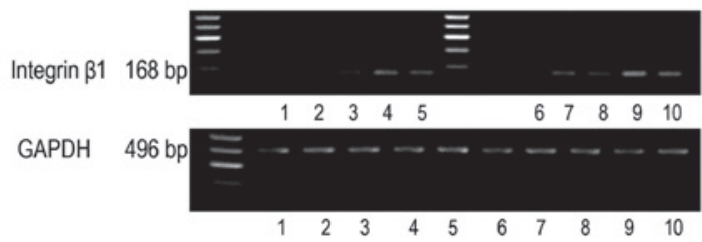

Figure 3. DS inhibits the growth of celiac-implanted tumour nodules and the expression of integrin $\beta 1$ in in vivo experiments. (A) A significant decrease in the number of celiac-implanted tumour nodules was observed from days 3 and 14 in the DS group. (B) 3,3'-Diaminobenzidine was used as a staining agent (brown). Positive staining for integrin $\beta 1$ expression was observed in the cytoplasm. Cells negative for integrin $\beta 1$ were stained by haematoxylin. (magnification, $x 400$ ). (C) The expression of integrin $\beta 1$ mRNA had significantly decreased in the DS group at each time point from day 3 to 14 when compared with the control group at the corresponding time points. Lanes 1-5 represent days 1,3,7 and 14, and the time of natural death, respectively, in the control group. Lanes 6-10 represent days 1, 3, 7 and 14, and the time of natural death, respectively, in the DS group. DS, dextran sulphate; GAPDH, glyceraldehyde-3 phosphate dehydrogenase.

\section{Results}

DS causes MKN1 cells to lose connection. In the control group, the MKN1 cells exhibited a spindle or flat morphology, forming a monolayer via mutual contact between the cells after plating for $4 \mathrm{~h}$. In the DS group, a number of the cells were non-adherent. The majority of the adherent cells retained a round shape, and contact between the cells was rarely observed (Fig. 1).

$D S$ inhibits the expression of integrin $\beta 1$ in MKN1 cells. In the control group, following $2 \mathrm{~h}$ of culture, the cell membrane of the MKN1 cells contained integrin $\beta 1$ that formed clusters on the underside of the cells. The cells were connected by pseudopodia that strongly expressed integrin $\beta 1$. In the DS group, the cell membrane contained integrin $\beta 1$, but no clusters were observed (Fig. 2A). The MKN1 cells formed pseudopodia and attached to the culture dish after treatment. After $2 \mathrm{~h}$ of culture, large integrin $\beta 1$ clusters had formed on the bottom of the cells. The cells became flat and formed multiple large pseudopodia. After treatment with DS for 30 and $60 \mathrm{~min}$, the size of the integrin $\beta 1$ clusters decreased, and the pseudopodia became shorter and then disappeared over time (Fig. 2B). Adherent cells in the control and DS groups, and non-adherent cells in the DS group expressed integrin $\beta 1$. The integrin $\beta 1 \mathrm{mRNA}$ expression levels of the adherent and free cells in the DS group were reduced to 74 and 38\% compared with the control group (Fig. 2C).

$D S$ inhibits the growth of celiac-implanted tumour nodules and the expression of integrin $\beta 1$ in in vivo experiments. The celiac-implanted tumour nodules in the DS and control groups were assessed. The number of tumour nodules on the greater omentum, abdominal wall and superior mesenteric increased over time following injection of the DS and cells. In the control group, the tumour nodules on the greater omentum appeared the earliest, and the omentum presented the greatest number of nodules. There was a significant decrease $(\mathrm{P}<0.010)$ in the number of celiac-implanted tumour nodules at each time point from day 3 to 14 in the DS group compared to the control group (Table I; Fig. 3A). The integrin $\beta 1$ protein was positively expressed in the cytoplasm as a brown colour in the tumour cells. The amount of positive immunoreactivity was higher in the control group than in the DS group on the day $14(\mathrm{P}<0.001$; Table II; Fig. 3B). The expression of integrin $\beta 1 \mathrm{mRNA}$ had significantly decreased in the DS group at each time point from day 3 to 14 when compared with the control group at the corresponding time points $(\mathrm{P}<0.010$; Table III; Fig. 3C).

\section{Discussion}

The diagnosis rate of advanced gastric cancer is $37-39 \%$, and $>50 \%$ of patients with stage I-III gastric cancer experience post-operative recurrence with subsequent development to an advanced stage (12). Peritoneal metastasis is the main cause of mortality from gastric cancer, and can even be caused by surgery (12). Presently, chemotherapy is the main comprehensive treatment; however, due to the lack of specificity, the effect of chemotherapeutics is insufficient, even with multiple therapies (12). Patients with early-stage gastric cancer usually do not present with symptoms; therefore, the disease has often developed to an advanced stage when the patients are diagnosed, and $~ 50 \%$ of patients with advanced-stage cancer develop peritoneal metastases (12). Thus, there is an urgent requirement to develop therapies to prevent the peritoneal metastasis of gastric cancer, and DS may be such a potential medicine.

The metastasis of gastric cancer cells is a complex multistep process, involving invasion, adhesion, migration and other types of malignant biological behaviours (13). In particular, it involves three successive steps: i) Tumour invasion such that tumour cells leave the mucosa of the stomach; ii) migration of the non-adherent cancer cells into the abdominal cavity, where they adhere to the peritoneum; and iii) invasion and novel capillary formation with proliferation around the vasculature, with eventual formation of nodules of metastatic carcinoma (14). 
Among the numerous factors that affect tumour invasion and metastasis, integrins are gaining increasing attention due to their unique structure and function. Integrins comprise a transmembrane protein family composed of dimers of two subunits, $\alpha$ and $\beta$, and integrin $\beta 1$ dimerises with different $\alpha$ subunits to constitute the vast majority of integrin complexes in the extracellular matrix (14). Integrins mainly function in two ways in the occurrence and development of tumours: i) Mediating the adhesion of tumour cells to the extracellular matrix by changing the composition of the substrate and adjusting the biological function of the matrix to promote the invasion and metastasis of tumour cells; and ii) mediating messages from the extracellular matrix to cells, as this information often affects cell growth and differentiation (14). The transfer of abnormal information by integrin promotes tumour cell growth, dedifferentiation and distant metastasis (15).

Cell migration is necessary for tumour invasion and metastasis, and can be divided into several steps: the polarisation of cells, the budding of the cell membrane, actin contraction, movement of cells at adhesion areas, and the separation of the tail and base of cells (16). The ligands of integrins include extracellular matrix components, such as fibronectin, fibrinogen, collagen, vitronectin and laminin, which mediate interactions between cells and the extracellular matrix, and promote cell adhesion and the formation of novel tissues (16). Integrin activation triggers cell signalling that leads to the reorganisation of the cytoskeleton and causes cell morphology changes (17). Studies on the formation of integrin clusters and the migration of cells indicate that integrin is transferred from the trailing edge of the cell to the front of the cell, initiating the formation of local adhesion areas at the tip of the pseudopodia (18).

Studies have suggested that the abnormal expression of integrin on the surface of tumour cells may be directly associated with the invasion and metastasis of the tumour. Integrin mediates adhesion between cells, induces angiogenesis, and plays a significant role in the metastasis and infiltrating growth of the malignant tumour $(19,20)$. Integrin $\beta 1$ is an important element in the integrin family and plays a key role in gastric cancer cell adhesion to the peritoneum by mediating the adhesion between cancer cells and various fibres of the peritoneal base layer, allowing cancer cells to adhere to the peritoneal layer (21). Intraperitoneal injection of a monoclonal antibody against integrin $\beta 1$ can significantly reduce adhesion, inhibit the peritoneal implantation of cancer cells and reduce the number of peritoneally implanted nodules (22).

The present in vitro experiment demonstrated that the expression of integrin $\beta 1 \mathrm{mRNA}$ in adherent cells in the experimental group was reduced to $74 \%$ of the level in the control group, and that the expression level of integrin $\beta 1$ cDNA in free-floating cells in the experimental group was reduced to $38 \%$ of that in the control group. This result showed that DS inhibited the expression of integrin $\beta 1$ quantitatively. Fluorescence immunostaining showed that DS inhibited the expression of integrin $\beta 1$ and reduced integrin clustering, thus indicating that DS inhibited the expression of integrin $\beta 1$ qualitatively. Additionally, DS prevented MKN1 cells from forming pseudopodia and changing shape to become morphologically stable. When the cells were treated with DS prior to adherence, a number were unable to adhere, and the majority of the adherent cells maintained a round shape. When the cells were treated with DS once they had adhered, their pseudopodia became shorter or smaller. In this experiment, the integrin $\beta 1$ clustering also decreased. Thus, DS may inhibit integrin $\beta 1$ activity, preventing cytoskeleton reorganisation and inhibiting the adhesion of MKN1 cells to the culture dish.

The in vivo experiment showed that the number of celiac-implanted tumour nodules increased significantly with the duration of cancer cell injection. At the same time point, the number of carcinoma nodules on the greater omentum in the experimental group was decreased compared with that in the control group. Integrin $\beta 1$ immunoreactivity in the experimental group was also decreased compared with that in the control group. Thus, DS may inhibit integrin $\beta 1$ expression to reduce the abdominal metastasis of the gastric cancer cells.

In summary, the in vivo and in vitro experiments showed that DS inhibits integrin $\beta 1$ expression together with the adhesion and celiac metastasis of cancer cells.

\section{Acknowledgements}

This study was supported by Ningxia Science and Technology Support Project (grant no., NXKZ20130068).

\section{References}

1. Jemal A, Siegel R, Xu J and Ward E: Cancer statistics, 2010. CA Cancer J Clin 60: 277-300, 2010.

2. Wang J, Yu JC, Kang WM and Ma ZQ: Treatment strategy for early gastric cancer. Surg Oncol 21: 119-123, 2011.

3. Liu Y: Gastric cancer. In: Surgery. Wang X and Wang J (eds). Volume 8. People's Health Publication, Beijing, pp360-365, 2014.

4. Wang $\mathrm{Z}$ and Chen L. Present status of treatment in peritoneal metastasis of gastric cancer. Zhonghua Wei Chang Wai Ke Za Zhi 18: 194-197, 2015 (In Chinese).

5. Broll R, Weschta M, Windhoevel U, Berndt S, Schwandner O, Roblick U, Schiedeck TH, Schimmelpenning H, Bruch HP and Duchrow M: Prognostic significance of free gastrointestinal tumor cells in peritoneal lavage detected by immunocytochemistry and polymerase chain reaction. Langenbecks Arch Surg 386: 285-292, 2001.

6. Maehara Y, Hasuda S, Koga T, Tokunaga E, Kakeji Y and Sugimache K: Postoperative outcome and sites of recurrence in patients following curative resection of gastric cancer. Br J Surg 87: 353-357, 2000.

7. Yonemura Y, Bandou E, Kawamura T, Endou Y and Sasaki T: Quantitative prognostic indicators of peritoneal dissemination of gastric cancer. Eur J Surg Oncol 32: 602-606, 2006.

8. Orr AW, Ginsberg MH, Shattil SJ, Deckmyn H and Schwartz MA: Matrix-specific suppression of integrin activation in shear stress signalling. Mol Biol Cell 17: 4686-4697, 2006.

9. Niu $\mathrm{G}$ and Chen $\mathrm{X}$ : Why integrin as a primary target for imaging and therapy. Theranostics 1: 30-47, 2011.

10. Hagiwara A, Sawai K, Sakakura C, Shirasu M, Ohgaki M, Imanishi T, Yamasaki J, Togawa T and Takahashi T: Prevention of peritoneal metastasis of cancer with dextran sulfate-an experimental study in mice. Anticancer Drugs 8: 894-897, 1997.

11. Chervoneva I, Li Y, Schulz S, Croker S, Wilson C, Waldman SA and Hyslop T: Selection of optimal reference genes for normalization in quantitative RT-PCR. BMC Bioinformatics 11: 253, 2010.

12. Pasechnikov V, Chukov S, Fedorov E, Kikuste I and Leja M: Gastric cancer: Prevention, screening and early diagnosis. World J Gastroenterol 20: 13842-13862, 2014.

13. Valastyan S and Weinberg RA: Tumor metastasis: Molecular insights and evolving paradigms. Cell 147: 275-292, 2011.

14. Singh SR: Gastric cancer stem cells: A novel therapeutic target. Cancer Lett 338: 110-119, 2013.

15. Humphries MJ: Integrin structure. Biochem Soc Trans 28: 311-339, 2000.

16. Trepet X, Chen Z and Jacobson K. Cell Migration. Compr Physiol 2: 2369-2392, 2012. 
17. Giancotti FG and Ruoslahli E: Integrin signalling. Science 285: 1028-1032, 1999.

18. Zamir E, Katz M, Posen Y, Erez N, Yamada KM, Katz BZ Lin S, Lin DC, Bershadsky A, Kam Z and Geiger B: Dynamics and segregation of cell matrix adhesions in cultured fibroblasts. Nat Cell Biol 2: 191-196, 2000.

19. Yano H, Mazaki Y, Kurokawa K, Hanks SK, Matsuda M and Sabe H: Roles played by a subset of integrin signaling molecules in cadherin-based cell-cell adhesion. J Cell Biol 166: 283-295, 2004.
20. Janssen M, Frielink C, Dijkgraf I, Oyen W, Edwards DS, Liu S, Rajopadhye M, Massuger L, Corstens F and Boerman O: Improved tumor targeting of radiolabeled RGD peptides using rapid does fractionation. Cancer Biother Radiopharm 19: 399-404, 2004.

21. Lynch L, Vodyanik PI, Boettiger D and Guvakova MA: Insulin-like growth factor I controls adhesion strength mediated by alpha5 beta lintegrins in motile carcinoma cells. Mol Biol Cell 16: 51-63, 2005.

22. Howe GA and Addison C: $\beta 1$ integrin: An emerging player in the modulation of tumorigenesis and response to therapy. Cell Adh Migr 6: 71-77, 2012. 